\title{
Blunt abdominal trauma with small bowel injury: are isolated lesions riskier than associated lesions? ${ }^{1}$
}

\author{
Trauma abdominal fechado com lesão de intestino delgado: lesão isolada tem mais \\ risco de complicações do que a associada?
}

\author{
Gustavo Pereira Fraga ${ }^{\mathrm{I}}$, Fernando Henrique Bergo de Souza e Silva ${ }^{\mathrm{II}}$, Nicolle Antunes de Almeida ${ }^{\mathrm{III}}$ Jorge Carlos \\ Machado Curi ${ }^{\mathrm{iv}}$ Mario Mantovaniv $^{\mathrm{V}}$ \\ ${ }^{\text {I }}$ PhD, Post PhD Fellow, University of California, San Diego (UCSD), Assistant Professor, Division of Trauma, School of Medicine (FCM), \\ University of Campinas (UNICAMP), Brazil. \\ II Graduate Student of FCM - UNICAMP and Scientific Initiation Student - FAPESP. Campinas-SP, Brazil. \\ III MD, Ex-Member of Trauma League of UNICAMP, Campinas-SP, Brazil. \\ Iv MD, Assistant Surgeon, Division of Trauma Surgery, FCM - UNICAMP, Campinas-SP, Brazil. \\ v PhD, Chairman and Head of Division of Trauma Surgery, FCM - UNICAMP, Campinas-SP, Brazil.
}

\begin{abstract}
Purpose: The objective of this study was to compare patients with "isolated" blunt small bowel injury (SBI) to patients with multiple intra-abdominal injuries and analyze whether delayed laparotomy affected outcome. Methods: Medical records of patients that suffered a blunt SBI between 1994 and 2005 were reviewed. The patients were divided into two groups: those with isolated SBI and those with other associated intra-abdominal injuries ("non-isolated"). The method of diagnosis, time to operation, small bowel Organ Injury Scale (OIS) assessment (grade $\geq 2$ ), injury severity score (ISS), morbidity, and mortality were analyzed. Results: A total of 90 patients met the inclusion criteria, including 62 (68.9\%) isolated cases and $28(31.1 \%)$ non-isolated cases. Isolated cases required more supplementary diagnostic methods than the non-isolated cases. Non-isolated cases had a shorter diagnosis to treatment period $(\mathrm{p}<.01)$ and a higher ISS (mean 22.5 vs. 17.2 in "isolated" group). Morbidity (51.6\% and 53.6\%) and mortality (16.1\% and 28.6\%) did not differ significantly between the isolated and non-isolated groups. Delays in diagnosis were common in the isolated group, but this did not affect outcome. Patients with associated injuries, and higher ISS, had higher mortality. Conclusions: The presence of associated intra-abdominal injuries significantly affected the presentation and time to diagnosis of patients with SBI, but not morbidity or mortality. Delayed surgical treatment in the isolated cases was not associated with an increased incidence of complications. Patients inflicted with more severe associated injuries were less likely to survive the trauma.
\end{abstract}

Key words: Trauma. Small bowel. Jejunum. Ileum. Intestinal fistula.

\section{RESUMO}

Objetivo: Comparar pacientes com lesão "isolada" de intestino delgado com pacientes com lesões abdominais "associadas" e analisar o quanto o retardo para indicação de laparotomia influenciou na evolução dos pacientes. Métodos: Foram revisados os prontuários de pacientes com trauma abdominal fechado e lesão de intestino delgado no período de 1994 a 2005, sendo os pacientes divididos em dois grupos: lesão "isolada" e lesões abdominais "associadas". Foram analisados os métodos diagnósticos, intervalo de tempo para a cirurgia, gravidade da lesão de delgado (grau $\geq 2$ ), ISS e morbimortalidade dos pacientes. Resultados: Noventa pacientes preencheram os critérios de inclusão, 62 (68,9\%) no grupo "isolada" e 28 $(31,1 \%)$ no "associada". Pacientes do grupo "isolada" necessitaram mais de métodos diagnósticos complementares. O tempo de diagnóstico até o tratamento foi significantemente menor no grupo "associada", e estes pacientes apresentavam ISS mais elevado (média de 22,5 versus 17,2 no grupo "isolada"). A morbidade e mortalidade nos grupos foram, respectivamente, $51,6 \%$ e 16,1\% no grupo "isolada", e 53,6\% e 28,6\% no "associada", sem diferença estatística. Demora para o diagnóstico foi comum no grupo "isolada", porém sem agravar a evolução dos pacientes. Pacientes com lesões "associadas", quantificadas pelo ISS, tiveram maior mortalidade. Conclusão: A presença de lesões abdominais "associadas" significativamente interferiu no quadro clínico e momento do diagnóstico em pacientes com lesão de delgado, porém não influenciou na morbimortalidade. No grupo "isolada" a demora para tratamento cirúrgico foi freqüente, porém sem interferir nas complicações. A elevada mortalidade foi reflexo da gravidade de lesões associadas.

Descritores: Trauma. Intestino delgado. Jejuno. Íleo. Fístula intestinal.

1. Research performed at Division of Trauma Surgery, Department of Surgery, Faculty of Medicine (FCM), State University of Campinas (UNICAMP), Brazil 


\section{Introduction}

Blunt small bowel injury (SBI) is rarely diagnosed despite the fact that injuries to the jejunum and ileum are the most common lesions in cases of penetrating abdominal trauma. Although SBI has been reported to be the third most common injury in blunt abdominal trauma, it was diagnosed in only $1.1 \%$ of admissions after blunt injury and in only $0.3 \%$ of patients had SBI perforation in a multiinstitutional study ${ }^{1}$. Few centers have significant experience with these injuries and most institutions have a low incidence of SBI diagnosis ${ }^{2-6}$.

A better understanding of the mechanism of trauma and types of SBI is needed since the diagnosis of these injuries remains problematic. The diagnosis is notoriously difficult, especially in patients with multiple injuries, head trauma or impaired consciousness. The introduction of abdominal computerized tomography (CT) imaging as the primary diagnostic method in cases of blunt abdominal trauma and the acceptance of non-operative management for solid organ injury have increased the risk of missed small bowel injury ${ }^{7-9}$. The diagnosis of SBI is now more frequently made on the basis of clinical signs or an abnormal CT scan, than as an associated injury during a trauma laparotomy. As a result, delays in the diagnosis of SBI may occur and contribute significantly to morbidity and mortality ${ }^{1,5,7,10}$.

The objective of this study was to analyze the outcome of patients suffering from jejunal and ileal injuries after blunt abdominal trauma. Specifically, we compared the diagnostic methods utilized, the time to treat the patients, complications, and mortality between "isolated" SBI and "non-isolated" (multiple abdominal injuries) SBI cases.

\section{Methods}

This study employed a retrospective, descriptive, case-control design. Data were collected from the registries of 1,739 patients submitted to laparotomy during a 12-year period (January $1^{\text {st }}, 1994$ to December 31, 2005) at the Division of Trauma Surgery of the State University of Campinas (UNICAMP). Patients were classified based on the types and locations of their injuries. Data were collected only from trauma patients with confirmed blunt SBI limited to the jejunum and ileum. Patients who were less than 14 years of age were not included in this study because they were treated by the pediatric emergency division. The sequence of diagnostic and therapeutic procedures adopted was in agreement with standards established by ATLS ${ }^{\text {ò11 }}$.

All small bowel wounds were graded for injury severity according to the Organ Injury Scaling (OIS) Committee of the American Association for the Surgery of
Trauma from the operative findings ${ }^{12}$. Patients with grade I injury (small bowel contusion or hematoma without devascularization, or partial thickness but no perfuration) were excluded because these lesions did not require surgical repair. Individual chart reviews from patients who met the initial inclusion criteria were conducted with protected patient confidentiality and the study was approved by the institutional ethical committee; informed consent was not required. Data were collected on medical history, demographics, physical examination findings, diagnostic studies, the time from the traumatic event until admission and operative treatment, surgical findings and operative procedures, any other injuries, Injury Severity Score (ISS) ${ }^{13}$, complications, and outcome.

Physical examination, diagnostic peritoneal lavage (DPL), abdominal CT scan and ultrasonography were the diagnostic means available. Patients were classified as having immediate surgery if treated within $6 \mathrm{~h}$ of being injured or as having delayed diagnosis if treated after $\geq 6 \mathrm{~h}$. Patients were classified as "isolated" SBI if they did not have other abdominal injuries requiring surgical intervention, or as "non-isolated" if they had jejunal and ileal injuries in association with other intra-abdominal injuries that did require surgical repair. SBI-related complications included the presence of a fistula, intraabdominal abscess formation, and peritonitis. Deaths were classified by cause and attributed to SBI if confirmed to be the result of a peritoneal complication. The data were analyzed with Epi-Info 6.04 software and compared by Chisquared analysis; $p$ values less than 0.05 were considered significant.

\section{Results}

Of the 1,739 patients submitted to laparotomy after abdominal trauma during the study period, $30.5 \%$ had blunt trauma. Injury of the jejunum or ileum was confirmed in 431 patients, and 96 patients had blunt SBI ( $18.1 \%$ of patients with blunt trauma). Six patients with grade I injury were excluded. The remaining 90 patients who constituted the study group had small bowel full-thickness perforation.

There were 77 male $(85.6 \%)$ and 13 female patients $(14.4 \%)$. Their mean age was 39.9 years. Forty-four patients $(48.9 \%)$ were between 20 and 40 years of age, and only 6 patients were more than 60 years old.

The mechanisms of injury are listed in Table 1. Abdominal pain was the most frequent symptom and associated tenderness was present in $46.7 \%$ of the cases during examination. The physical symptoms and signs upon presentation to the hospital are summarized in Table 2. Of the 50 patients injured in car accidents, fifteen $(30 \%)$ had a transverse bruise from their seat belt.

TABLE 1 - Mechanisms of injury.

\begin{tabular}{lll}
\hline Mechanisms of injury & Number of cases & \% \\
Motor vehicle crash, car & 50 & 55.5 \\
Pedestrian struck & 12 & 13.3 \\
Physical assault & 9 & 10.0 \\
Motor vehicle crash, motorcycle & 6 & 6.7 \\
Fall & 5 & 5.6 \\
Sports accident & 3 & 3.3 \\
Other & 5 & 5.6 \\
Total & 90 & 100.0 \\
\hline
\end{tabular}


TABLE 2 - Clinical signs upon admission.

\begin{tabular}{llc}
\hline Symptoms & Number of cases & \% \\
Pain & 68 & 75.6 \\
Abdominal wall bruising & 43 & 47.8 \\
Abdominal tenderness & 42 & 46.7 \\
Bruise from the seat belt & 15 & 16.7 \\
Fever & 6 & 6.7 \\
Vomiting & 5 & 5.6 \\
\hline
\end{tabular}

Supplementary diagnostic methods were used in 59 patients $(65.6 \%)$. DPL was performed in 26 cases $(28.9 \%)$ and was considered positive in all but 2 cases $(92.3 \%$ positive). The 2 patients $(7.7 \%)$ that were initially missed were operated on within $24 \mathrm{~h}$ and $72 \mathrm{~h}$, respectively, and the latter developed an intra-abdominal abscess. Ultrasonography was utilized in 8 patients $(8.9 \%)$. CT imaging was done in 23 patients $(25.6 \%)$ and $87 \%$ of those showed suggestive signs of SBI; specifically $82.6 \%$ had free fluid, $60.9 \%$ had mesenteric fat obliteration, and $39.1 \%$ had extraluminal air. In $3(13 \%)$ patients the initial CT scan appeared to be normal.

The most frequent grade of injury severity (OIS) in operative findings was grade II (44 patients, 48.9\%) (Figure 1). Sixty-two patients $(68.9 \%)$ had isolated small bowel injuries, and $28(31.1 \%)$ had SBI in association with other intra-abdominal injuries. The types of other intra-abdominal injuries suffered by patients in the study group are listed in Table 3.

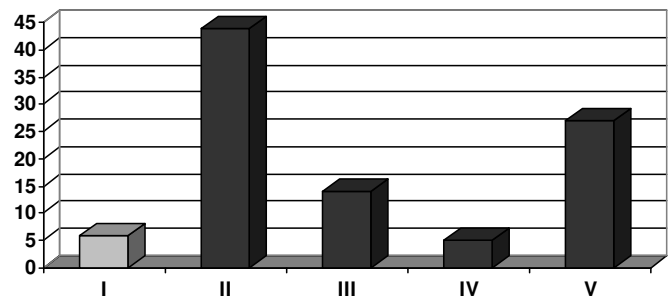

FIGURE 1 - Frequency of SBI by grade ${ }^{12}$. Only patients with grade II-V were included in this study.

TABLE 3 - Summary of associated injuries in non-isolated group.

\begin{tabular}{lll}
\hline Organ affected & Number of cases & \% \\
Colon & 18 & 20.0 \\
Liver & 12 & 13.3 \\
Spleen & 7 & 7.8 \\
Stomach & 3 & 3.3 \\
Other & 11 & 12.2 \\
\hline
\end{tabular}

Physical examination of the abdomen dictated laparotomy in a significantly higher number of patients with non-isolated SBI than in those with isolated SBI. In the non-isolated group, 15 patients $(53.6 \%)$ underwent laparotomy on the basis of the clinical evaluation of the abdomen, while in the isolated group only 16 patients $(25.8 \%)$ were subjected to immediate surgical intervention $(p<0.05)$.
Hypovolemic shock occurred in $28.6 \%$ of patients with multiple injuries and in $3.2 \%$ of patients with isolated SBI. The time that elapsed between trauma and laparotomy was $<6 \mathrm{~h}$ in $19.7 \%$ of patients with isolated SBI and in $55.2 \%$ of patients with non-isolated SBI (Figure 2). Patients with multiple intra-abdominal injuries underwent laparotomy significantly sooner than those with isolated SBI $(p<0.01)$.

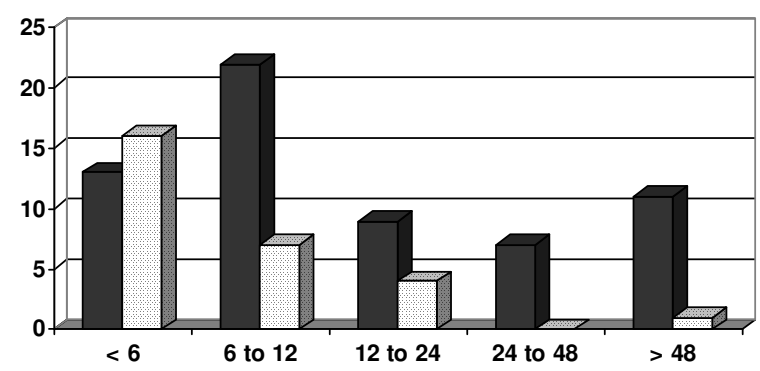

FIGURE. 2. Time elapsed between trauma and surgical treatment. 
The overall complication rate for all patients was $52.2 \%$ (47 cases). Table 4 shows a comparison of the complications that occurred in patients from each group. The morbidity rate was similar between the two groups
(53.6\% in the non-isolated group vs. $51.6 \%$ in the isolated group). Patients with multiple intra-abdominal injuries presented a higher rate of anastomotic fistula $(10.7 \%)$ than patients in the isolated injury group $(6.4 \%)$.

TABLE 4 - Main complications in patients with non-isolated $v s$. isolated SBI.

\begin{tabular}{|c|c|c|c|c|c|}
\hline \multirow[t]{2}{*}{ Morbidity } & \multirow{2}{*}{$\begin{array}{l}\text { All Patients }(n=90) \\
\text { Number }\end{array}$} & \multicolumn{2}{|c|}{ Non-isolated $(n=28)$} & \multicolumn{2}{|c|}{ Isolated $(n=62)$} \\
\hline & & Number & $\%$ & Number & $\%$ \\
\hline Some complication & 47 & 15 & 53.6 & 32 & 51.6 \\
\hline Sepsis & 10 & 2 & 7.1 & 8 & 12.9 \\
\hline Pulmonary & 10 & 3 & 10.7 & 7 & 11.3 \\
\hline Coagulophaty & 10 & 8 & 28.6 & 2 & 3.2 \\
\hline Wound infection & 9 & 2 & 7.1 & 7 & 12.9 \\
\hline Anastomotic fistula & 7 & 3 & 10.7 & 4 & 6.4 \\
\hline Deaths & 18 & 8 & 28.6 & $\mathbf{1 0}$ & $\overline{16.1}$ \\
\hline
\end{tabular}

Complication rates did not differ significantly $(p=$ 0.29 ) between patients with perforated SBI who had their repair performed within $6 \mathrm{~h}(62 \%)$ and those surgically treated after more than $6 \mathrm{~h}(47.5 \%)$. Of the 32 isolated SBI patients who suffered complications, $24(75 \%)$ had operative repair more than $6 \mathrm{~h}$ post-injury. However, time elapsed to operative repair did not significantly affect morbidity in either group.

Not surprisingly, the ISS average was higher in the non-isolated group than in the isolated group (22.5 vs. 17.2). The overall mortality rate was $20 \%$ (18 cases), with 8 deaths $(28.6 \%)$ in the non-isolated group and 10 deaths $(16.1 \%)$ in the isolated group (group comparison, $p=0.28$ ). The mortality in patients with an ISS $>25$ was $58.8 \%$ and that in patients with an ISS < 25 was $11 \%$; thus mortality was clearly related to injury severity $(p<0.001)$.

\section{Discussion}

Estimates of the incidence of small bowel rupture associated with blunt abdominal injury range from 3 to $18 \% \%^{1,2,4,6,14,15}$. The increased prevalence of non-operative management for victims of blunt trauma and the use of CT imaging as the preferred diagnostic test have reduced the number of laparotomies performed in the recent years. The frequency of SBI in blunt abdominal trauma in the present study group, $18.1 \%$, is comparable with previous reports in the literature.

Mechanisms of small bowel disruption with blunt trauma include shearing forces, compression between the abdominal wall and vertebral column, and bursting injury due to a sudden increase in intraluminal pressure ${ }^{2}$. Motor vehicle accidents are the main cause of blunt SBI 1,3,4,5,6,7,10. The increase in seat belt use has resulted in lower fatality rates and injury severity, but has been accompanied by a concomitant increase in rates of intestinal injuries ${ }^{8}$. Although the incidence of SBI appears to be lower in children than in adults, a study with 13 children inflicted with SBI reported that the majority $(69 \%)$ had been involved in motor vehicle accidents ${ }^{10}$. In the present series, motor vehicle crashes were the main cause $(55.5 \%)$ of SBI.
Serial clinical evaluations of the abdomen are extremely useful in the diagnosis of SBI, particularly in patients with additional associated intra-abdominal injuries. A bruise across the abdomen inflicted by a seat belt ("seat belt sign") and ongoing abdominal pain are known associated risk factors of SBI. Fakhry et al. ${ }^{7}$ observed that $67.7 \%$ of 198 patients with blunt SBI initially presented with signs or symptoms highly suggestive of this lesion, and $84.3 \%$ were taken to the operating room without delay. In this study, of the patients involved in motor vehicle crashes, only $30 \%$ had the abdominal seat belt sign, which is less than that commonly reported in the literature (nearly $50 \%)^{6,7}$. Consistent with prior reports ${ }^{1,2,3,4,6,7,14}$, the most frequent clinical signs were abdominal pain upon admission (75.6\%) and abdominal tenderness upon physical examination $(46.7 \%)$.

Diagnosis of these injuries remains problematic. Early recognition of SBI is important in the prevention of morbidity. DPL is more sensitive than CT imaging for diagnosis of SBI; however, in many cases, it results in nontherapeutic laparotomy. In our series, of the 26 patients (28.9\%) who underwent initial DPL, 24 (92.3\%) were correctly diagnosed, and the other two patients that were initially missed were operated on with a delay. DPL was the diagnostic method of choice for evaluating blunt abdominal injury in the past, but recently has been often replaced by CT imaging. Several authors however have expressed that DPL is an important adjunct in cases where SBI is suspected $^{1,5,7,14}$. CT imaging is newer than DPL, and it has become popular in recent years. The major advantages of CT include noninvasiveness, capacity to quantify free fluid, the ability to select patients with solid organ injury for nonoperative management, and the ability to view retroperitoneal organs $1,5,7,10,16,17,18$.

Breen et al. ${ }^{16}$ retrospectively assessed the CT findings of 19 patients with surgically revealed blunt SBI or mesenteric injury and concluded that findings of peritoneal fluid with no visible solid organ injury ( $58 \%$ of the cases) is an important sign of SBI; this finding has been replicated in several studies ${ }^{11,17,18,19}$. Frick et al. ${ }^{17}$ studied 70 patients with blunt SBI; delayed surgical intervention was undertaken in 
15 of the patients $(22.4 \%$ of 67 patients that had been subjected to laparotomy) who had initial CT scans without evidence of a lesion but had subsequent changes in physical status. Kemmeter et al. ${ }^{5}$ reviewed 69 patients with blunt SBI and found that 13 of the cases (38\%) had enteric injuries that were missed by the initial CT scan. Fang et al. ${ }^{14}$ reported a $10.2 \%$ (5 out of 49 scans) false-negative rate in patients that had SBI with perforation. In a multi-institutional study with 518 patients subjected to abdominal trauma CT imaging, free fluid was the most common finding, noted in $71.6 \%$ of the patients, $21.1 \%$ of whom had perforated SBI; $13 \%$ of the patients who had perforating SBI revealed during a laparotomy had a normal preoperative abdominal CT scan ${ }^{1}$. Thompson and Holland ${ }^{10}$ treated 13 children with blunt perforating SBI who underwent abdominal CT scans; all 13 had radiological abnormalities. Saku et al. ${ }^{19}$ analyzed the CT findings of 12 patients with SBI perforation due to blunt trauma, 5 of whom were given a pre-surgical follow-up CT. All 9 patients that were examined $>8 \mathrm{~h}$ post-injury, but none of the 4 examined within $4 \mathrm{~h}$, presented with extraluminal air, suggesting that the incidence of extraluminal air increases as time elapses, prompting the authors to recommend a repeat CT, particularly after $8 \mathrm{~h}$, in suspect cases to increase sensibility ${ }^{19}$. Mitsuhide et al. ${ }^{20}$ suggested the use of a repeat CT scan or laparoscopy to prevent nontherapeutic laparotomy and delayed diagnosis in patients with suspected blunt SBI. In our series, the falsenegative CT scan rate was $13 \%$, consistent with previously published rates ${ }^{1,14,17,19}$

Patients who had a small bowel hematoma or serosal tear, but no perforation, were excluded from this study. Guarino et al. ${ }^{4}$ described that only $41.6 \%$ of patients with blunt injuries had bowel perforations. Watts et al. ${ }^{15}$ studied 2,632 blunt trauma patients with hollow viscus injuries and the percentage of patients with full-thickness perforation of the small bowel was $25.7 \%$. The present study was retrospective and the medical record was the source of our data, therefore some patients with grade I SBI may have skipped, explaining the low incidence of patients excluded with this injury severity.

The frequency of isolated SBI in blunt abdominal trauma reported in the literature ranges from $31.4 \%$ to $59 \%$ 1,2,6,15. A relatively high rate, $68.9 \%$, of the patients in our study had isolated SBI. These patients needed more supplementary diagnostic testing and underwent laparotomy significantly later than those with non-isolated SBI, but they did not have increased mortality. Robbs et al. ${ }^{2}$ observed that multiple injuries carried a mortality rate of $57.8 \%$, which was significantly greater than the $21.2 \%$ that attended isolated jejunal perforations, and that the mortality was significantly higher in patients not treated within $24 \mathrm{~h}$ of injury. Fang et al. ${ }^{14}$ observed that a delay in surgery of more than $24 \mathrm{~h}$ after the injury in patients with perforated SBI did not significantly increase mortality, but was associated with a dramatic increase in the incidence of complications. In a multi-center study with 198 patients, the percentage of patients with delayed diagnosis did not differ between isolated SBI patients and those with multiple injuries ${ }^{7}$. Meanwhile in another multi-institutional review, patients with perforated SBI treated within $8 \mathrm{~h}$ of being injured had a significantly lower complication rate than those treated later, and patients with isolated SBI that was repaired after $24 \mathrm{~h}$ of being injured had a higher mortality rate $(15 \%)$ than those treated sooner $(4 \%)^{1}$.

The mortality rates reported here are within the range (4\%-32\%) previously reported ${ }^{1-7}$. The difference between the mortality rates of isolated $(16.1 \%)$ and nonisolated patients $(28.6 \%)$ was not statistically significant in our study even though the ISS for patients with multiple injuries was higher than for patients with isolated SBI. However given that Robbs et al. ${ }^{2}$ did find a significantly higher mortality rate in multiple-injury cases than in isolated jejunal perforation cases, it may be that we did not have sufficient statistical power in this study to reveal the difference.

\section{Conclusion}

The diagnosis of SBI was influenced by the presence of other intra-abdominal injuries. The non-isolated group had a higher mortality rate than the isolated group; however, this was not directly related to the SBI. Morbidity and mortality in both the isolated and non-isolated SBI cases were independent of the injury to treatment delay.

\section{References}

1. Fakhry SM, Watts DD, Luchette FA. Current diagnostic approaches lack sensitivity in the diagnosis of perforated blunt small bowel injury: Analysis from 275,557 trauma admissions from the EAST Multi-Institutional HVI Trial. J Trauma. 2003;54:295-306.

2. Robbs JV, Moore SW, Pillay SP. Blunt abdominal trauma with jejunal injury: A review. J Trauma. 1980;20(4):308-11.

3. Mantovani M, Curi JCM, Rizoli SB. Exclusive jejunal and ileal lesions due to blunt trauma. Rev Paul Med. 1992;110(2):56-8.

4. Guarino J, Hassett Jr JM, Luchette FA. Small bowel injuries: mechanisms, patterns, and outcome. J Trauma. 1995;39(6):1076-80.

5. Kemmeter PR, Senagore AJ, Smith D, Oostendorp L. Dilemmas in the diagnosis of blunt enteric Trauma. Am Surg. 1998;64:750-4.

6. Neugebauer H, Wallenboeck E, Hungerford M. Seventy cases of injuries of the small intestine caused by blunt abdominal trauma: A retrospective study from 1970 to 1994. J Trauma. 1999;46(1):11621.

7. Fakhry SM, Brownstein M, Watts DD, Baker CC, Oller D. Relatively short diagnostic delays $(<8$ hours) produce morbidity and mortality in blunt small bowel injury: an analysis of time to operative intervention in 198 patients from a multicenter experience. J Trauma. 2000;48(3):408-15.

8. Brownstein MR, Bunting T, Meyer AA, Fakhry SM. Diagnosis and management of blunt small bowel injury: A survey of the membership of the American Association for the Surgery of Trauma. J Trauma. 2000;48(3):402-8.

9. Shapiro MB, Nance ML, Schiller HJ, Hoff WS, Kauder DR, Schwab CW. Nonoperative 
management of solid abdominal organ injuries from blunt trauma: impact of neurologic impairment. Am Surg. 2001;67:793-6.

10. Thompson SR, Holland AJA. Perforating small bowel injuries in children: influence of time to operative operation on outcome. Injury. 2005;36:1029-33.

11. American College of Surgeons. Committee on Trauma. Advanced Trauma Life Support ATLS ${ }^{\circ}$. Instructor manual. Chicago: American College of Surgeons, $7^{\text {th }}$ ed., 2003.

12. Moore EE, Cogbill TH, Malangoni MA, Jurkovich GJ, Champion HL, Gennarelli TA, McAninch JW, Pachter HL, Shackford SR, Trafton PG. Organ injury scaling, II: pancreas, duodenum, small bowel, colon, and rectum. J Trauma. 1990;30(11):1427-9.

13. Baker SP, O'Neill B, Haddon Jr W, Long WB.: The Injury Severity Score: a method for describing patients with multiple injuries and evaluating emergency care. J Trauma. 1974;14:187-96.

14. Fang JF, Chen RJ, Lin BC, Hsu YB, Kao JL, Kao YC, Chen MF. Small bowel perforation: is urgent surgery necessary? J Trauma. 1999;47(3):515-20.

15. Watts DD, Fakhry SM. Incidence of hollow viscus injury in blunt trauma: An analysis from 275,557 trauma admissions from EAST Multi-Institutional Trial. J Trauma. 2003;54:289-94.

16. Breen DJ, Janzen DL, Zwirewich CV, Nagy AG. Blunt bowel and mesenteric injury: diagnostic performance of CT signs. J Comput Assist Tomogr. 1997;21(5)706-12.

17. Frick EJ Jr, Pasquale MD, Cipolle MD. Small-bowel and mesentery injuries in blunt trauma. J Trauma. 1999;46(5):920-6.

18. Yegiyants S, Abou-Lahoud G, Taylor E. The management of blunt abdominal trauma patients with computed tomography scan findings of free peritoneal fluid and no evidence of solid organ injury. Am Surg. 2006;72(10):943-6.
19. Saku M, Yoshimitsu K, Murakami J, Nakamura Y, Oguri S, Noguchi T, Ayukawa K, Honda H. Small bowel perforation resulting from blunt abdominal trauma: interval change of radiological characteristics. Radiat Med. 2006;24:358-64.

20. Mitsuhide K, Junichi S, Atsushi N, Masakazu D, Shinobu H, Tomohisa E, Hiroshi Y. Computed tomographic scanning and selective laparoscopy in the diagnosis of blunt bowel injury: a prospective study. J Trauma. 2005;58(4):696-703.

Conflict of interest:none

Correspondence:

Gustavo Pereira Fraga

Av. Cel. Silva Telles, 211 ap. 3

13024-000 Campínas-SP, Brazil

(55-19) 3294-6348

fragagp@uol.com.br
Financial source: Foundation of Support to Research of the State of São Paulo

(FAPESPProc.n.04/07869-3)

Received: August 23, 2007

Review: October 18, 2007

Accepted : November 28, 2007

\section{How to cite this article}

Fraga GP, Souza e Silva FHB, Almeida NA, Curi CM, Mantovani M. Blunt abdominal trauma with small bowel injury: are isolated lesions riskier than associated lesions? Acta Cir Bras. [serial on the Internet] 2008 March-Apr;23(2). Available from URL: http://www.scielo.br/acb 